\title{
Does the Shape of the Drinking Receptacle Influence Taste/Flavour Perception? A Review
}

\author{
Charles Spence $^{1, *}$ (1) and George Van Doorn ${ }^{2}$ \\ 1 Crossmodal Research Laboratory, Department of Experimental Psychology, University of Oxford, \\ South Parks Road, Oxford OX1 3UD, UK \\ 2 School of Health Sciences and Psychology, Department of Psychology, Federation University Australia, \\ Northways Road, Churchill 3842, Australia; george.vandoorn@federation.edu.au \\ * Correspondence: charles.spence@psy.ox.ac.uk; Tel.: +44-1865-271364
}

Academic Editor: Edgar Chambers IV

Received: 3 June 2017; Accepted: 29 June 2017; Published: 6 July 2017

\begin{abstract}
In this review, we summarize the latest evidence demonstrating that the shape and feel of the glassware (and other receptacles) that we drink from can influence our perception of the taste/flavour of the contents. Such results, traditionally obtained in the world of wine, have often been interpreted in terms of changes in physico-chemical properties (resulting from the retention, or release, of specific volatile aromatic molecules), or the differing ways in which the shape of the glassware funnels the flow of the liquid across the tongue. It is, however, not always clear that any such physico-chemical differences do, in fact, lead to perceptible differences. Others, meanwhile, have stressed the importance of cultural factors, and the perceived appropriateness, or congruency, of the receptacle to the drink, based on prior experience. Here, though, we argue that there is also a much more fundamental association at work between shape properties and taste/flavour. In particular, the suggestion is made that the shape properties of the drinking receptacle (e.g., whether it be more rounded or angular) — regardless of whether the receptacle is seen, felt, or both-can prime certain expectations in the mind of the drinker. And, based on the theory of crossmodal correspondence, this priming is thought to accentuate certain aspects of the tasting experience, likely as a result of a taster's attention being focused on the attributes that have been subtly primed.
\end{abstract}

Keywords: shape; drinking receptacle; taste; flavour; crossmodal correspondences; priming; attention; gastrophysics

\section{Introduction}

When we drink, we nearly always drink from some kind of receptacle, be it a glass, mug, cup, can, or bottle. While a great deal of research has examined the influence of the chemical composition of the receptacle's contents on the multisensory perception of flavour, far fewer studies have considered the impact of the drinking vessel on people's perception. That said, a growing body of empirical research now demonstrates just how important the sensory properties of the receptacle are to people's perception of the contents, no matter what they might be. In this review, we highlight the impact of the curvature of the drinking receptacle on taste/flavour perception. While the majority of the research on glassware has focused on the world of wine (see Spence, 2011 [1], for a review), it is worth noting that there has also long been an interest in serving different cocktails in particular glasses 
(e.g., [2]). And, more recently, the global craft beer revolution has seen renewed interest in optimizing the glassware in that sector too (Wells, 2015 [3]). ${ }^{1}$

\section{Assessing the Role of Culture and Congruency on the Impact of the Drinking Receptacle}

Culture and prior experience undoubtedly play an important role in determining our perception (e.g., see Bremner, Caparos, Davidoff, de Fockert, Linnell, \& Spence, 2013 [5]; Van Doorn, Woods, Levitan, Wan, Velasco, Bernal-Torres, \& Spence, 2017 [6]; Wan, Woods, Jacquot, Knoeferle, Kikutani, \& Spence, 2016 [7]; Wan, Woods, Seoul, Butcher, \& Spence, 2015 [8]). Indeed, a number of studies have demonstrated that people tend to rate drinks more favourably when they are presented in receptacles that are judged as being congruent (given their prior experience) with the contents, relative to when the same drink is presented in a receptacle that is deemed to be incongruent with the contents (Raudenbush, Meyer, Eppich, Corley, \& Petterson, 2002 [9]; Schifferstein, 2009 [10]; see also Cardello, Maller, Masor, Dubose, \& Edelman, 1985 [11]). Consistent with Schifferstein's findings [10], the participants in a series of cross-cultural online studies conducted by Wan, Zhou, Woods, and Spence (2015) [12] were willing to pay significantly more for a beer if it was served in a dimpled beer mug than in a highball or a wine glass instead. Wan and her colleagues' participants also preferred the look of the beer when it was presented in the dimpled beer mug rather than in any of the other types of glassware that were tested. Furthermore, red and white wines were liked more, and the participants reported being willing to pay significantly more for them if the glassware was deemed congruent with the contents. Such findings further highlight the influence of content-context congruency on people's subjective ratings and willingness-to-pay for the contents of the drinking receptacle. ${ }^{2}$

Here, though, we wish to stress that beyond any cultural associations that different groups of individuals may have with particular styles of glassware (Standage, 2007 [16]), there are also more fundamental associations between what we feel in the hand (and/or what we see, given that it is hard to dissociate the two as we rarely pick up a glass without inspecting it visually first; see Spence \& Gallace, 2011 [17]) and taste/flavour perception that deserve consideration.

\subsection{On the Shape of the Wine Glass: Physico-Chemical Explanations for the Impact of Glassware}

Over the years, researchers have conducted a number of studies in order to assess the impact of the glassware on people's perception of wine, testing both experts and social drinkers (e.g., Cliff, 2001 [18]; Delwiche \& Pelchat, 2002 [19]; Fischer \& Loewe-Stanienda, 1999 [20]; Hummel, Delwiche, Schmidt, \& Hüttenbrink, 2003 [21]; see Spence, 2011 [1], for a review). However, while great care and attention has been paid by some individuals (and companies) to matching the glassware to the style of wine (or grape variety), it is still not entirely clear whether the discoveries in this field (e.g., changes in the shape of the drinking receptacle influencing perceived aroma in expert wine tasters, say; see Vilanova, Vidal, \& Cortés, 2008 [22]) would necessarily extend to other people's (e.g., social drinkers) perception of other, often less complex, drinks, such as cola or perhaps even beer.

Some highly-respected authorities have suggested that changes in glass shape lead to a change in the flow of the liquid across the tongue (Peynaud, 1996 [23]). However, empirical evidence is rarely provided in order to support such assertions-namely, that the flow properties really do differ, or that any such differences really do impact the multisensory tasting experience. Meanwhile, technical measurement has unequivocally demonstrated that the chemical composition of the aromatic

1 Though it should be noted that in the case of glassware for beer, the shape may be as much about assuring a good head (i.e., optimizing eye-appeal) as it is enhancing the aromatics (see Agnew, 2015 [4]).

2 That being said, changing the receptacle in which a drink is presented can, on occasion, be used to increase sales. Just think, for instance, about the so-called Latin gin revival that has taken place in recent years. This has been closely linked to a change in the glassware that this drink is typically served in. Specifically, the distinctive Copa de balon glass (looking like a heavy-bowl shaped red wine glass, Willis, 2015 [13]; see Spence \& Wan, 2015 [14], 2016 [15], for reviews) normally associated with one category (i.e., wine) has, in this case, been adapted for use by another (i.e., gin). 
headspace over a wine is significantly affected by the shape of the glass (see, for example, the extensive work on headspace analysis over sparkling wine by Liger-Belair and colleagues; e.g., see Liger-Belair, Beaumont, Vialatte, Jégou, Jeandet, \& Polidori, 2008 [24]; Liger-Belair, Bourget, Pron, Polidori, \& Cilindre, 2012 [25]). However, evidence of a significant difference in the chemical composition of the headspace over a drink does not necessarily guarantee that any differences will be perceptible to the expert, let alone the social drinker (see also Russell, Zivanovic, Morris, Penfield, \& Weiss, 2005 [26]; and Priest \& Stewart, 2006 [27], on beer). Here it is worth bearing in mind that perceptual constancy (i.e., the tendency to perceive the attributes of a familiar stimulus as constant despite sometimes dramatic changes in peripheral stimulation occurring) has been demonstrated to exist in olfactory perception, just as it has in the other senses (Gottfried, 2010 [28]; Teghtsoonian \& Teghtsoonian, 1984 [29]).

\subsection{How Receptacle Shape Influences Taste/Flavour Ratings}

Interestingly, a trio of independent studies (Cavazzana, Larsson, Hoffmann, Hummel, \& Haehner, 2017 [30]; Mirabito, Oliphant, Van Doorn, Watson, \& Spence, 2017 [31]; van Rompay, Finger, Saakes, \& Fenko, 2016 [32]) that have just been published in the journal Food Quality and Preference all converge on the view that varying the shape properties of the receptacle in which a drink is served can influence people's ratings of the taste/aroma/flavour of the contents. In particular, these studies have investigated everything from soft drinks to beer, and from bitter coffee to sweet hot chocolate, serving them in rounder versus more angular/straight-sided drinking receptacles.

In Cavazzana et al.'s (2017) [30] study, 100 participants had to evaluate the taste and aroma of a cola drink (and a sparkling water) served in one of three different receptacles: a cola glass, a water glass, and a plastic bottle (see Figure 1). Participants rated the intensity and pleasantness of the drink's aroma. Next, they tasted the drink and rated intensity, sweetness, sourness, saltiness, bitterness and carbonation. Ratings were made on 100-point Visual Analog Scales (VAS). The participants rated 6 drinks in total ( 2 drinks $\times 3$ receptacles). The aroma of the cola drink was rated as tasting significantly more pleasant and intense when served in a typical cola glass than when served in a water glass or plastic bottle instead. (The aroma of the water was also rated as more intense and pleasant when the drink was served in the water glass rather than the bottle.) The cola drink was rated as tasting sweeter from the cola glass, whereas carbonation ratings for both drinks were higher in the plastic bottle. Unfortunately, however (and as recognized by the authors themselves), differences in the weight of these drinking receptacles may have contributed to differences in the ratings ascribed to the drink's sensory qualities (Barnett, Velasco, \& Spence, 2016 [33]; Cantor, 2009 [34]; cf. Gatti, Spence, \& Bordegoni, 2014 [35], on the effect of weight on fragrance intensity). Similarly, the flimsy feel of the plastic bottle, when compared to the two firm glasses, may also have played a role in biasing people's ratings (see Krishna \& Morrin, 2008 [36]). Rather than being criticisms of Cavazzana et al.'s study [30], though, these potential caveats simply highlight the various challenges that are associated with conducting research using everyday drinking receptacles/materials. Nevertheless, it is crucial to remember that if one wants to make claims about the specific influence of curvature vs. straight-sided glassware, such factors obviously need to be controlled for. 


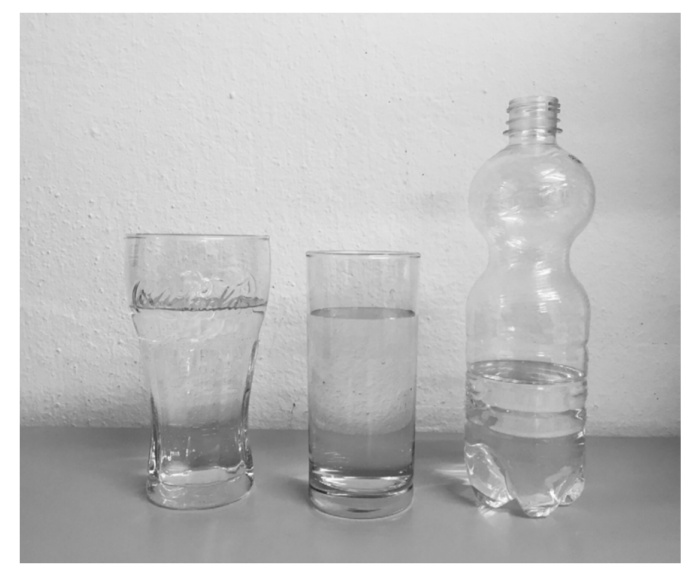

Figure 1. The three drinking receptacles used in Cavazzana et al.'s (2017) [30] study: A typical cola glass (left), a typical water glass (middle), and a plastic bottle (right). Note that each container was filled with $200 \mathrm{~mL}$ of liquid. Reproduced with permission from [30], (c) 2017 Elsevier Ltd.

Mirabito et al. (2017) [31] conducted a study in Australia in which they demonstrated that people $(N=53$ participants tested using a within-participants experimental design) rated an Australian craft beer (using 10-point Likert scales) as tasting significantly fruitier when served from a beer glass with rounded, rather than straight, sides (see Figure 2A). The shape of the glass had no significant effect on people's ratings of Aroma pleasantness, Bitterness of the taste, Pleasantness, Sweetness, or Willingness-to-Pay. Importantly, the weight of the glasses was matched in this study (using small weights attached to the bottom of the glasses). Nevertheless, ratings of the beer's fruitiness (a pale ale) were $\sim 13 \%$ higher when the participants tasted the beer from the curved, rather than the straight-sided, glass. ${ }^{3}$ The participants' ratings of the 'intensity' of the beer were also influenced by changes in the curvature of the glassware. Specifically, the 'intensity' of the beer's taste/flavour was rated $\sim 6 \%$ higher when the participants tasted the beer from the glass with the curved rather than the straight sides. These results therefore demonstrate that receptacle curvature is associated with fruitiness and flavour intensity even when the weight and flexibility of the drinking vessels have been fixed. It is interesting to note that much the same conclusion about 'fruitiness' was reached some years ago by Hummel et al. (2003) [21], but related specifically to aroma. Specifically, 181 people with a normal sense of smell, rated the fruitiness of the aroma of both red and white wines as significantly higher when they were served in a rounded (bulbous), rather than straight-sided, wine glass (see Figure 2B).

Finally, van Rompay et al. (2016) [32] have recently demonstrated that the outside texture of a receptacle influenced people's ratings of both a bitter-tasting coffee and a sweet tasting chocolate drink. In their study, the exterior of two cup holders were 3D printed in order to achieve either a more angular or a more rounded surface texture (see Figure 3). One-hundred and sixty participants were tested. The results revealed that: (1) bitterness ratings were $\sim 27 \%$ higher for the cup holder with the angular surface pattern relative to the cup holder with the more rounded surface pattern; and (2) sweetness ratings were $\sim 18 \%$ higher for the cup holder with the rounded surface pattern than for the cup holder with the more angular surface pattern. Taste intensity ratings were higher for the angular cup than for the round cup. As far as it is possible to tell, the weight and compressibility of the two cup holders were matched in this study. This, again, implies that the only way in which the two receptacles differed was in terms of their angular vs. rounded feel (and/or visual appearance; Spence \& Gallace, 2011 [17]). And given that it was only the outside of the receptacles that varied, physico-chemical accounts clearly do not have any possible explanatory validity here.

3 Note here that many people, including experts, have been shown to confuse sweetness and fruitiness when evaluating beverages, e.g., sparkling wines (see Harrar, Smith, Deroy, \& Spence, 2013 [37]). 


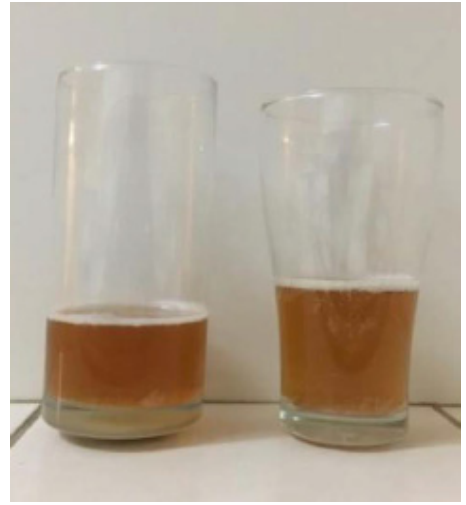

(A)

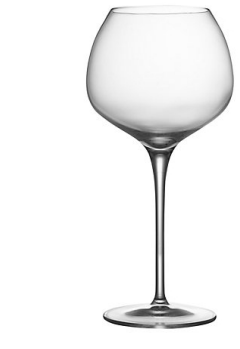

Bulbous

Higher odour intensity, greater complexity, preferred

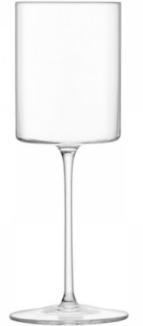

Straight-sided Higher sourness

(B)

Figure 2. (A) Side-view of the straight and curved glasses with $100 \mathrm{~mL}$ Yenda Pale Ale in each glass as used in Mirabito et al.'s (2017) study [31]; (B) Summary of the key result to emerge from Hummel et al.'s (2003) [21] study of the impact of glass shape on the perception of fruity aroma in wine. (A) is reproduced with permission from [31], (C) 2017 Elsevier Ltd.

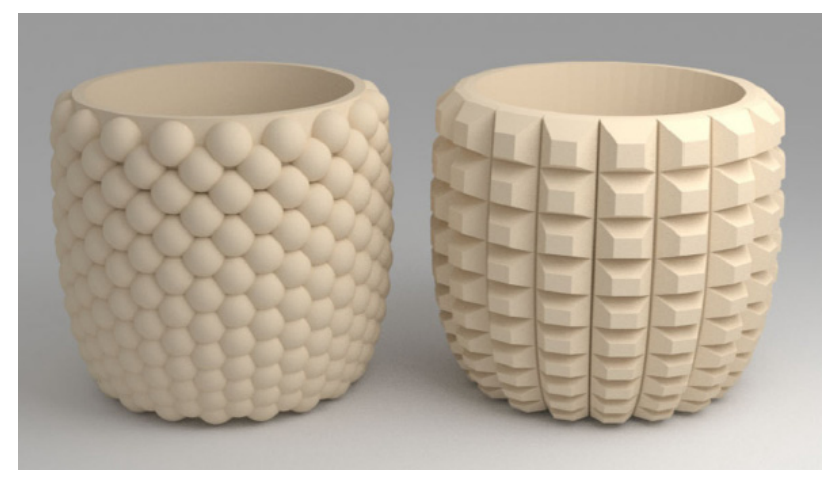

Figure 3. The 3D printed exteriors for the drinks held by participants in van Rompay et al. (2016) [32]. Finalized surface pattern variants (left panel: rounded surface pattern; right panel: angular surface pattern). Reproduced with permission from [32], () 2016 Elsevier Ltd.

Relevant here in relation to the influence of shape on the perceived taste of coffee are the results of a study by Van Doorn, Colonna-Dashwood, Hudd-Baillie, and Spence (2015) [38]. These researchers demonstrated that people rated the quality a coffee served with rounded latte art (looking rather like a chocolate amoeba shaken on top of the coffee) as higher than the same coffee when a more angular star-shaped pattern was sprinkled on top of the drink instead. Parenthetically, participants' cost estimates were also higher for the coffee with rounded latte art. However, and relevant to van Rompay et al.'s (2016) [32] work, people expected the coffee displaying angular-shaped latté art to be more bitter than the coffee with a round shape on it. 


\subsection{Crossmodal Correspondences between Shape Properties and Taste/Flavour}

The reason(s) as to why the shape of the drinking receptacle should affect people's rating of the contents is not absolutely certain. In fact, there may well be several factors at play. As we have seen already, both culture/prior experience, and physico-chemical factors likely play some role here. However, beyond that, what is also clear is that many of the studies that have been conducted over the last decade or so have unequivocally shown that sweet-tasting foods (e.g., chocolate) and drinks (e.g., fruit juices) tend to be associated with rounder forms, whereas bitter and sour tastes tend to be more strongly associated with angular shapes (e.g., Cytowic \& Woods, 1982 [39]; Deroy \& Valentin, 2011 [40]; Dichter, 1971 [41]; Gal, Wheeler, \& Shiv, 2007 [42]; Liang, Roy, Chen, \& Zhang, 2013 [43]; Liang, Biswas, Vinnakota, Fu, Chen, Quan, Zhan, \& Roy, 2016 [44]; Ngo, Misra, \& Spence, 2011 [45]; Ngo, Piqueras-Fiszman, \& Spence, 2012 [46]; Spence, 2012 [47], 2013 [48], 2014 [49]; Spence \& Deroy 2012 [50], 2013 [51]; Velasco, Woods, Deroy, \& Spence, 2015 [52]; see Velasco, Woods, Petit, Cheok, \& Spence, 2016 [53], for a review). What is more, the research on crossmodal correspondences also shows that people associate particular aromas (e.g., raspberry) with specific shape properties (e.g., roundness; see Hanson-Vaux, Crisinel, \& Spence, 2013 [54]; Seo, Arshamian, Schemmer, Scheer, Sander, Ritter, \& Hummel, 2010 [55]).

Going beyond the basic crossmodal correspondence (or association) between taste and shape properties, it has been reported that serving desserts off rounder, rather than more angular (e.g., squared), plates can result in their being rated as tasting significantly sweeter (see Chen, Woods, \& Spence, in press [56]; Stewart \& Goss, 2013 [57]; though see also Piqueras-Fiszman, Alcaide, Roura, \& Spence, 2012 [58]). Obviously, physico-chemical accounts of such results would seem implausible here too. As such, one suggestion based on the theory of crossmodal correspondences (see Spence, 2012 [47]), is that shape properties (no matter whether they are seen or touched) that are associated with specific tastes/flavours may prime those sensory attributes in the mind of the taster. And, by priming these sensory attributes, the consumer's attention is subtly drawn towards them which, in turn, enhances the perception of them (Spence, 2012 [47]). Here, then, we would like to argue that the latest findings demonstrating that rounder drinking receptacles result in drinks being rated as tasting/smelling sweeter/fruitier (Hummel et al., 2003 [21]; Mirabito et al., 2017 [31]; van Rompay et al., 2016 [32]) fit with this growing literature stressing the importance of crossmodal correspondences.

So far in this review, the impact of the basic shape properties of drinking receptacles on the multisensory tasting experience has been demonstrated. We have outlined various explanations for such effects that have been put forward over the years. It is therefore time to ask whether people (i.e., glassware designers) have internalized the crossmodal correspondences between shape and tastes / flavour in the designs associated with particular brands that one finds in the marketplace or, put differently, do designers intuitively use the in the drinking receptacles that they create to convey an impression about a drink's likely, or distinctive, taste profile? In this regard, one need think only of the Leffe Hoeggarden glass with its distinctively angular/straight sides, or the angular shape that one finds on the stem of a Stella Artois chalice glass (see Figure 4).

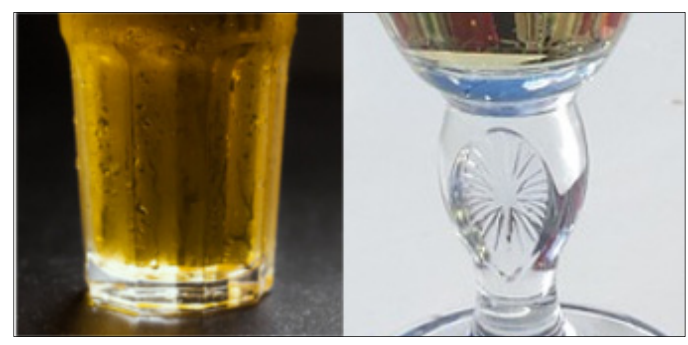

Figure 4. Two commercial examples of glassware using angularity. Angular-sided Hoegaarden glass, and angularity on stem of Stella Artois chalice, detail from [59]. 
A growing number of commentators from different categories have, in recent years, started to stress the importance of marketing/using appropriately-shaped glassware for different drinks (see Stead, Angus, Macdonald, \& Bauld, 2014 [60]; The Ice Maiden, 2016 [2]). Some have suggested that the recent trend for distinctive glassware for beer really started in 2007 with the Samuel Adams' "Perfect Pint Glass" (Agnew, 2015 [4]) (see Figure 5). Furthermore, many commentators have suggested that changing the glassware can actually change people's perception of the product (Gray, 2015 [61]; Priest \& Stewart, 2006 [27]). This kind of claim/research runs hand-in-hand with the evidence showing that people's drinking behaviour is affected by the size/shape of the glassware (Anon, 2009 [62]; Attwood, Scott-Samuel, Stothart, \& Munafò, 2012 [63]; Matthews, 2017 [64]). ${ }^{4}$ However, without the relevant gastrophysics (i.e., the systematic study of the mind of the person doing the tasting; see Spence, 2017 [65]) research (and evidence), it can be difficult to separate the fact of the matter from the marketing hype that (sometimes) is associated with new glass launches (especially when these claims come from the glassware manufacturers). As an example of the latter, take Dogfish Head owner Sam Calagione describing a specially designed India Pale Ale (IPA) glass as like an "olfactory cannon", that supposedly concentrates and propels the aroma from the glass into the drinker's nose (quoted in Agnew, 2015 [4])!

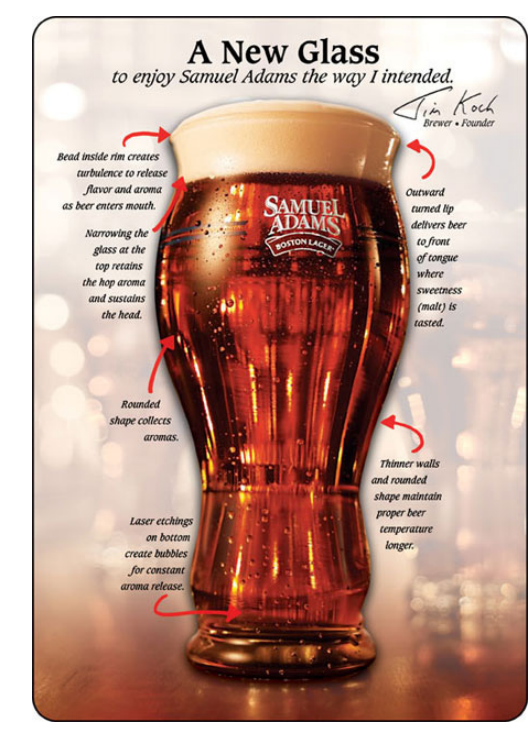

Figure 5. The Samual Adams “Perfect Pint Glass”. Reproduced from [66].

According to the trade press, matching the beer to the correct branded glassware, for instance, can increase sales by as much as a third (Anon, 2009 [62]). It is interesting here to note that no one has a wider range of glass shapes for their beer than the Belgians. Nevertheless, even within the English beer market, different brands are increasingly being associated with glassware or bottles of different shapes (see Agnew, 2015; Anon, 2009 [62]; Wells, 2015 [3]). The craft beer revolution has also resulted in beer producers/marketers thinking much more carefully about the optimum design of the branded glassware that is associated with their drinks.

Of course, given our general preference for curvature over angularity (e.g., Westerman, Gardner, Sutherland, White, Jordan, Watts, \& Wells, 2012 [67]; see Gómez-Puerto, Munar, \& Nadal, 2016 [68], for a recent historical overview), it could be suggested that opting for a rounder form for one's glassware ought, generally-speaking, to be preferred (over straight-sided glassware). However, that said, if a

4 This does, though, raise the question of whether any of the differences in drinking behaviour might not be attributable, at least in part, to any differences in the multisensory tasting experience that result from the change in the form/shape of the glassware. 
drink has a distinctively sour or bitter note, then one may wish to accentuate that feature by making sure that the drink is served in a glass that is more angular/straight-sided instead. The latter will likely be rated as more congruent, and may even be processed more efficiently as a result, with this increased 'perceptual fluency' leading to an increase in liking (Reber, Schwarz, \& Winkielman, 2004 [69]; Reber, Winkielman, \& Schwartz, 1998 [70]).

\section{Conclusions}

The latest sensory science research (what some are calling the new 'gastrophysics'; see Spence, 2017 [65]) is increasingly highlighting the influence of the basic sensory properties of drinking vessels (e.g., more rounded vs. more angular/straight-sided) on people's perception of a range of drinks and, importantly, differing attributes of those drinks (see also Becker, Van Rompay, Schifferstein, \& Galetzka, 2011 [71]). As such, in the years to come, we will likely see a growing number of studies investigating the consequences of the sensory properties of drinking vessels, evaluating everything from their weight (Barnett et al., 2016 [33]; Kampfer, Leischnig, Ivens, \& Spence, submitted [72]; Maggioni, Risso, Olivero, \& Gallace, 2015 [73]), texture (cf. Biggs, Juravle, \& Spence, 2016 [74]; Piqueras-Fiszman \& Spence, 2012 [75]; Slocombe, Carmichael, \& Simner, 2015 [76]; Tu, Yang, \& Ma, 2015 [77]), firmness/flexibility (Krishna \& Morrin, 2008 [36]), and material properties (Piqueras-Fiszman, Laughlin, Miodownik, \& Spence, 2012 [78]), not to mention their colour (Schifferstein, 2009 [10]), and presumably also thermal conductivity too (Bergmann Tiest, 2010 [79]; Bergmann Tiest, \& Kappers, 2009 [80]). Forward-thinking drink brands would be well advised to take heed of the latest research in order to develop signature glassware (i.e., that has a distinctive, and hence possibly branded, form) for their products. In the best-case scenario, this glassware should also deliver some kind of functional benefit in terms of the consumer's product experience. It will, though, be important to conduct the relevant gastrophysics research in order to move beyond the unsubstantiated marketing hype that one so often finds in this area to more evidence-based, neuroscience-inspired design. In closing, it is worth stressing a few notes of caution and directions for future research.

\section{Directions for Future Research}

First off, one key question that has not been addressed by any of the recent slew of studies on drinking receptacle shape is: How long-lasting are the effects? While culture and prior experience may help to set expectations of what receptacle shape is congruent for a given drink, novelty in glassware design (as in any other area) likely also has a certain appeal (and presumably influence over the consumer). However, the appeal and influence of novelty in glassware design will only have a short-lasting impact on sales. On the flip side, though, according to the cultural account, the impact of a particular shape might be expected to become stronger over time, as the shared meaning/associations becomes ever more firmly entrenched within society.

Relatedly, and as has been suggested previously, these crossmodal product-extrinsic effects on the multisensory tasting experience may well be more pronounced for those drinks that have a more complex taste profile to begin with (think craft beer, coffee, and wine, rather than carbonated water; see Spence, 2017 [65]).

It is also important to note that in the absence of the appropriate control studies, it is not possible to say for certain whether it is the expectation set by the visual appearance of the shape of the drinking vessel (see Van Doorn et al., 2015 [38], 2017 [6]), or the tactile/haptic properties that are doing the work in terms of changing people's ratings of a drink (see Piqueras-Fiszman \& Spence, 2015 [81]; Spence \& Gallace, 2011 [17]).

In the future, therefore, while our growing understanding of the impact of the shape of the drinking receptacle on the multisensory tasting experience may enable designers to enhance the experience for consumers, it will be important to recognize the trade-off that exists between the enhanced multisensory tasting experience that results from drinking receptacles with curved sides, 
on the one hand, and the increased consumption that such curved-sided glassware may give rise to (Attwood et al., 2012 [63]; Hope, 2015 [82]).

In conclusion, the results of a growing body of research demonstrate that our perception of many drinks is influenced by the shape of the receptacle in which that drink is presented (see Cavazzana et al., 2017 [30]; Hummel et al., 2003 [21]; Mirabito et al., 2017 [31]; van Rompay et al., 2016 [32]). While the underpinning science unequivocally explaining such results is not there yet, the evidence that has been published to date clearly shows that the effects of shape on taste/flavour (not to mention consumption behaviour) would appear to go beyond any cultural associations that we may have internalized, and also beyond any physico-chemical differences that different glassware might sometimes elicit. Ultimately, we may need to incorporate a role for the crossmodal correspondences between shape properties and the chemical senses in order to fully explain what is going on.

While the focus of this article has been on the impact of the shape of the receptacle on taste/flavour perception, it is worth noting that the drinkability, consumption rate, and thirst-quenching character of beverages may also be affected by the shape of a receptacle.

Acknowledgments: Charles Spence would like to thank the AHRC grant entitled 'Rethinking the senses' (AH/L007053/1) for supporting this research.

Conflicts of Interest: The authors declare no conflicts of interest.

\section{References}

1. Spence, C. Crystal clear or gobbletigook? World Fine Wine 2011, 33, 96-101.

2. The Ice Maiden. A Beginner's Guide to Becoming A Mixologist! Part 2: Glassware. The Ice Co., 26 January 2016. Available online: http://www.theiceco.co.uk/blog/a-beginners-guide-to-becoming-a-mixologistpart-2-glassware/ (accessed on 2 July 2017).

3. Wells, J. Does the Shape of Your Glass Affect How a Beer Tastes? The Telegraph. 29 July 2015. Available online: http:/ / www.telegraph.co.uk/men/thinking-man/11765323/Does-the-shape-of-your-glass-affecthow-a-beer-tastes.html (accessed on 2 July 2017).

4. Agnew, M. Beer Glasses Get A New Shape. Star Tribune. 1 April 2015. Available online: http://www. startribune.com/beer-glasses-get-a-new-shape/298344291/ (accessed on 2 July 2017).

5. Bremner, A.J.; Caparos, S.; Davidoff, J.; de Fockert, J.; Linnell, K.J.; Spence, C. "Bouba" and "Kiki" in Namibia? A remote culture make similar shape-sound matches, but different shape-taste matches to Westerners. Cognition 2013, 126, 165-172. [CrossRef] [PubMed]

6. Van Doorn, G.; Woods, A.; Levitan, C.A.; Wan, X.; Velasco, C.; Bernal-Torres, C.; Spence, C. Does the shape of a cup influence coffee taste expectations? A cross-cultural, online study. Food Qual. Preference 2017, 56, 201-211. [CrossRef]

7. Wan, X.; Woods, A.T.; Jacquot, M.; Knoeferle, K.; Kikutani, M.; Spence, C. The effects of receptacle on the expected flavour of a coloured beverage: Cross-cultural comparison among French, Japanese, and Norwegian consumers. J. Sens. Stud. 2016, 31, 233-244. [CrossRef]

8. Wan, X.; Woods, A.T.; Seoul, K.-H.; Butcher, N.; Spence, C. When the shape of the glass influences the flavour associated with a coloured beverage: Evidence from consumers in three countries. Food Qual. Preference 2015, 39, 109-116. [CrossRef]

9. Raudenbush, B.; Meyer, B.; Eppich, W.; Corley, N.; Petterson, S. Ratings of pleasantness and intensity for beverages served in containers congruent and incongruent with expectancy. Percept. Mot. Skills 2002, 94, 671-674. [CrossRef] [PubMed]

10. Schifferstein, H.N.J. The drinking experience: Cup or content? Food Qual. Preference 2009, 20, 268-276. [CrossRef]

11. Cardello, A.V.; Maller, O.; Masor, H.B.; Dubose, C.; Edelman, B. Role of consumer expectancies in the acceptance of novel foods. J. Food Sci. 1985, 50, 1707-1714. [CrossRef]

12. Wan, X.; Zhou, X.; Woods, A.T.; Spence, C. Influence of the glassware on the perception of alcoholic drinks. Food Qual. Preference 2015, 44, 101-110. [CrossRef] 
13. Willis, A. Do you Use a Long Glass to Drink a G\&T? Why You've Got It All Wrong. Metro. 25 November 2015. Available online: http:/ / metro.co.uk/2016/11/25/do-you-use-a-long-glass-to-drink-a-gt-why-youve-gotit-all-wrong-6282806/ (accessed on 2 July 2017).

14. Spence, C.; Wan, I. Beverage perception \& consumption: The influence of the container on the perception of the contents. Food Qual. Preference 2015, 39, 131-140.

15. Spence, C.; Wan, I. Assessing the influence of the drinking receptacle on the perception of the contents. In Multisensory Flavor Perception: From Fundamental Neuroscience through to the Marketplace; Piqueras-Fiszman, B., Spence, C., Eds.; Elsevier: Duxford, UK, 2016; pp. 269-296.

16. Standage, T. A History of the World in Six Glasses; Atlantic Books: London, UK, 2007.

17. Spence, C.; Gallace, A. Multisensory design: Reaching out to touch the consumer. Psychol. Mark. 2011, 28, 267-308. [CrossRef]

18. Cliff, M.A. Influence of wine glass shape on perceived aroma and colour intensity in wines. J. Wine Res. 2001, 12, 39-46. [CrossRef]

19. Delwiche, J.F.; Pelchat, M.L. Influence of glass shape on wine aroma. J. Sens. Stud. 2002, 17, 19-28. [CrossRef]

20. Fischer, U.; Loewe-Stanienda, B. Impact of wine glasses for sensory evaluation. Int. J. Vine Wine Sci. 1999, 33, 71-80.

21. Hummel, T.; Delwiche, J.F.; Schmidt, C.; Hüttenbrink, K.-B. Effects of the form of glasses on the perception of wine flavors: A study in untrained subjects. Appetite 2003, 41, 197-202. [CrossRef]

22. Vilanova, M.; Vidal, P.; Cortés, S. Effect of the glass shape on flavor perception of "toasted wine" from Ribeiro (NW Spain). J. Sens. Stud. 2008, 23, 114-124. [CrossRef]

23. Peynaud, E. The Taste of Wine: The Art Science of Wine Appreciation, 2nd ed.; John Wiley \& Sons: New York, NY, USA, 1996.

24. Liger-Belair, G.; Beaumont, F.; Vialatte, M.-A.; Jégou, S.; Jeandet, P.; Polidori, G. Kinematics and stability of the mixing flow patterns found in champagne glasses as determined by laser tomography techniques: Likely impact on champagne tasting. Anal. Chim. Acta 2008, 621, 30-37. [CrossRef] [PubMed]

25. Liger-Belair, G.; Bourget, M.; Pron, H.; Polidori, G.; Cilindre, C. Monitoring gaseous $\mathrm{CO}_{2}$ and ethanol above champagne glasses: Flute versus coupe, and the role of temperature. PLoS ONE 2012, 7, e30628. [CrossRef] [PubMed]

26. Russell, K.; Zivanovic, S.; Morris, W.C.; Penfield, M.; Weiss, J. The effect of glass shape on the concentration of polyphenolic compounds and perception of Merlot wine. J. Food Qual. 2005, 28, 377-385. [CrossRef]

27. Priest, F.G.; Stewart, G.G. Handbook of Brewing, 2nd ed.; Taylor \& Francis: Boca Raton, FL, USA, $2006 ;$ p. 48.

28. Gottfried, J.A. Central mechanisms of odour object perception. Nat. Rev. Neurosci. 2010, 11, 628-641. [CrossRef] [PubMed]

29. Teghtsoonian, R.; Teghtsoonian, M. Testing a perceptual constancy model for odor strength: the effects of sniff pressure and resistance to sniffing. Perception 1984, 13, 743-752. [CrossRef] [PubMed]

30. Cavazzana, A.; Larsson, M.; Hoffmann, E.; Hummel, T.; Haehner, A. The vessel's shape influences the smell and taste of cola. Food Qual. Preference 2017, 59, 8-13. [CrossRef]

31. Mirabito, A.; Oliphant, M.; Van Doorn, G.; Watson, S.; Spence, C. Glass shape affects the perceived taste of beer. Food Qual. Preference 2017, in press.

32. Van Rompay, T.J.L.; Finger, F.; Saakes, D.; Fenko, A. "See me, feel me": Effects of 3D-printed surface patterns on beverage evaluation. Food Qual. Preference 2016. [CrossRef]

33. Barnett, A.; Velasco, C.; Spence, C. Bottled vs. canned beer: Do they really taste different? Beverages 2016, 2, 25. [CrossRef]

34. Cantor, D. Why Does Coke from A Glass Bottle Taste Different? Popular Science. 31 July 2009. Available online: http:/ / www.popsci.com/scitech/article/2009-07/why-does-coke-glass-bottle-plasticbottle-and-aluminum-can-taste-different (accessed on 2 July 2017).

35. Gatti, E.; Spence, C.; Bordegoni, M. Investigating the influence of colour, weight, \& fragrance intensity on the perception of liquid bath soap. Food Qual. Preference 2014, 31, 56-64.

36. Krishna, A.; Morrin, M. Does touch affect taste? The perceptual transfer of product container haptic cues. J. Consum. Res. 2008, 34, 807-818. [CrossRef]

37. Harrar, V.; Smith, B.; Deroy, O.; Spence, C. Grape expectations: How the proportion of white grape in Champagne affects the ratings of experts and social drinkers in a blind tasting. Flavour 2013, 2, 25. [CrossRef] 
38. Van Doorn, G.; Colonna-Dashwood, M.; Hudd-Baillie, R.; Spence, C. Latté art influences both the expected and rated value of milk-based coffee drinks. J. Sens. Stud. 2015, 30, 305-315. [CrossRef]

39. Cytowic, R.E.; Wood, F.B. Synaesthesia II: Psychophysical relations in the synaesthesia of geometrically shaped taste and colored hearing. Brain Cogn. 1982, 1, 36-49. [CrossRef]

40. Deroy, O.; Valentin, D. Tasting shapes: Investigating the sensory basis of cross-modal correspondences. Chemosens. Percept. 2011, 4, 80-90. [CrossRef]

41. Dichter, E. The strategy of selling with packaging. Package Engineering Magazine, July 1971, 16a-16c.

42. Gal, D.; Wheeler, S.C.; Shiv, B. Cross-Modal Influences on Gustatory Perception. 2007. Available online: http:/ / ssrn.com/abstract=1030197 (accessed on 2 July 2017).

43. Liang, P.; Roy, S.; Chen, M.-L.; Zhang, G.-H. Visual influence of shapes and semantic familiarity on human sweet sensitivity. Behav. Brain Res. 2013, 253, 42-47. [CrossRef] [PubMed]

44. Liang, P.; Biswas, P.; Vinnakota, S.; Fu, L.; Chen, M.; Quan, Y.; Zhan, G.; Roy, S. Invariant effect of vision on taste across two Asian cultures: India and China. J. Sens. Stud. 2016, 31, 416-422. [CrossRef]

45. Ngo, M.; Misra, R.; Spence, C. Assessing the shapes and speech sounds that people associate with chocolate samples varying in cocoa content. Food Qual. Preference 2011, 22, 567-572. [CrossRef]

46. Ngo, M.; Piqueras-Fiszman, B.; Spence, C. On the colour and shape of still and sparkling water: Implications for product packaging. Food Qual. Preference 2012, 24, 260-268. [CrossRef]

47. Spence, C. Managing sensory expectations concerning products and brands: Capitalizing on the potential of sound and shape symbolism. J. Consum. Psychol. 2012, 22, 37-54. [CrossRef]

48. Spence, C. Unravelling the mystery of the rounder, sweeter chocolate bar. Flavour 2013, 2, 28. [CrossRef]

49. Spence, C. Assessing the influence of shape and sound symbolism on the consumer's response to chocolate. New Food 2014, 17, 59-62.

50. Spence, C.; Deroy, O. On the shapes of tastes and flavours. Petits Propos. Culin. 2012, 97, 75-108.

51. Spence, C.; Deroy, O. Tasting shapes: A review of four hypotheses. Theor. ET Hist. Sci. 2013, 10, 207-238.

52. Velasco, C.; Woods, A.; Deroy, O.; Spence, C. Hedonic mediation of the crossmodal correspondence between taste and shape. Food Qual. Preference 2015, 41, 151-158. [CrossRef]

53. Velasco, C.; Woods, A.T.; Petit, O.; Cheok, A.D.; Spence, C. Crossmodal correspondences between taste and shape, and their implications for product packaging: A review. Food Qual. Preference 2016, 52, 17-26. [CrossRef]

54. Hanson-Vaux, G.; Crisinel, A.-S.; Spence, C. Smelling shapes: Crossmodal correspondences between odors and shapes. Chem. Senses 2013, 38, 161-166. [CrossRef] [PubMed]

55. Seo, H.-S.; Arshamian, A.; Schemmer, K.; Scheer, I.; Sander, T.; Ritter, G.; Hummel, T. Cross-modal integration between odors and abstract symbols. Neurosci. Lett. 2010, 478, 175-178. [CrossRef] [PubMed]

56. Chen, Y.-C.; Woods, A.; Spence, C. Sensation transference from plateware to food: The sounds and tastes of plates. Int. J. Food Des. 2017, in press.

57. Stewart, P.C.; Goss, E. Plate shape and colour interact to influence taste and quality judgments. Flavour 2013, 2, 27. [CrossRef]

58. Piqueras-Fiszman, B.; Alcaide, J.; Roura, E.; Spence, C. Is it the plate or is it the food? Assessing the influence of the color (black or white) and shape of the plate on the perception of the food placed on it. Food Qual. Preference 2012, 24, 205-208. [CrossRef]

59. Amazon. Stella Artois Belgian Chalice Beer Glasses 0.33L-Set of 4. Available online: https:/ / www.amazon. com/Stella-Artois-Belgian-Chalice-Glasses/dp/B00GJ40QPA (accessed on 2 July 2017).

60. Stead, M.; Angus, K.; Macdonald, L.; Bauld, L. Looking into the glass: Glassware as an alcohol marketing tool, and the implications for policy. Alcohol Alcohol. 2014, 49, 317-320. [CrossRef] [PubMed]

61. Gray, E. Let's Be Clear: Beer Glass Shapes. Stewart Brewing. 17 December 2015. Available online: https: / / www.stewartbrewing.co.uk/beerhead/lets-be-clear-glass-shapes/ (accessed on 2 July 2017).

62. Beer Matters: How Miller Brands Partners with Licensees to Drive Sales. The Publican. 24 July 2009. Available online: http:/ / www.morningadvertiser.co.uk/Drinks/Beer/Beer-Matters-How-Miller-Brandspartners-with-licensees-to-drive-sales (accessed on 2 July 2017).

63. Attwood, A.S.; Scott-Samuel, N.E.; Stothart, G.; Munafò, M.R. Glass shape influences consumption rate for alcoholic beverages. PLoS ONE 2012, 7, e43007. [CrossRef] [PubMed] 
64. Matthews, S. Size DOES Matter: Bigger Wine Glasses are Encouraging us to Drink Potentially Dangerous Amounts, Cambridge University Professor Claims. Daily Mail Online. 29 May 2017. Available online: http:/ / www.dailymail.co.uk/health/article-4551644/Bigger-wine-glasses-encouragingdrink-more.html (accessed on 2 July 2017).

65. Spence, C. Gastrophysics: The New Science of Eating; Viking Penguin: London, UK, 2017.

66. Building A Better Beer Glass. Available online: http://www.realbeer.com/edu/betterglass.php (accessed on 2 July 2017).

67. Westerman, S.J.; Gardner, P.H.; Sutherland, E.J.; White, T.; Jordan, K.; Watts, D.; Wells, S. Product design: Preference for rounded versus angular design elements. Psychol. Mark. 2012, 29, 595-605. [CrossRef]

68. Gómez-Puerto, G.; Munar, E.; Nadal, M. Preference for curvature: A historical and conceptual framework. Front. Hum. Neurosci. 2016, 9, 712. [CrossRef] [PubMed]

69. Reber, R.; Schwarz, N.; Winkielman, P. Processing fluency and aesthetic pleasure: Is beauty in the perceiver's processing experience? Personal. Soc. Psychol. Rev. 2004, 8, 364-382. [CrossRef] [PubMed]

70. Reber, R.; Winkielman, P.; Schwartz, N. Effects of perceptual fluency on affective judgments. Psychol. Sci. 1998, 9, 45-48. [CrossRef]

71. Becker, L.; Van Rompay, T.J.L.; Schifferstein, H.N.J.; Galetzka, M. Tough package, strong taste: The influence of packaging design on taste impressions and product evaluations. Food Qual. Preference 2011, 22, 17-23. [CrossRef]

72. Kampfer, K.; Leischnig, A.; Ivens, B.S.; Spence, C. Touch-taste-transference: Assessing the effect of the weight of product packaging on flavor perception and taste evaluation. PLOS ONE 2017. submitted for publication.

73. Maggioni, E.; Risso, P.; Olivero, N.; Gallace, A. The effect of a container's weight on the perception of mineral water. J. Sens. Stud. 2015, 30, 395-403. [CrossRef]

74. Biggs, L.; Juravle, G.; Spence, C. Haptic exploration of plateware alters the perceived texture and taste of food. Food Qual. Preference 2016, 50, 129-134. [CrossRef]

75. Piqueras-Fiszman, B.; Spence, C. The influence of the feel of product packaging on the perception of the oral-somatosensory texture of food. Food Qual. Preference 2012, 26, 67-73. [CrossRef]

76. Slocombe, B.G.; Carmichael, D.A.; Simner, J. Cross-modal tactile-taste interactions in food evaluations. Neuropsychologia 2015, 88, 58-64. [CrossRef] [PubMed]

77. Tu, Y.; Yang, Z.; Ma, C. Touching tastes: The haptic perception transfer of liquid food packaging materials. Food Qual. Preference 2015, 39, 124-130. [CrossRef]

78. Piqueras-Fiszman, B.; Laughlin, Z.; Miodownik, M.; Spence, C. Tasting spoons: Assessing how the material of a spoon affects the taste of the food. Food Qual. Preference 2012, 24, 24-29. [CrossRef]

79. Bergmann Tiest, W.M. Tactual perception of material properties. Vis. Res. 2010, 50, 2775-2782. [CrossRef] [PubMed]

80. Bergmann Tiest, W.M.; Kappers, A.M.L. Tactual perception of material properties. Atten. Percept. Psychophys. 2009, 71, 481-489. [CrossRef] [PubMed]

81. Piqueras-Fiszman, B.; Spence, C. Sensory expectations based on product-extrinsic food cues: An interdisciplinary review of the empirical evidence and theoretical accounts. Food Qual. Preference 2015, 40, 165-179. [CrossRef]

82. Hope, J. The Key to Sensible Drinking? Pick a Straight Glass-Not a Curved One: Speed at Which a Person Drinks Is Influenced by the Shape of Glass It Is Served In. Daily Mail Online. 6 May 2015. Available online: http://www.dailymail.co.uk/news/article-3069554/The-key-sensible-drinking-Pickstraight-glass-not-curved-one-Speed-person-drinks-influenced-shape-glass-served-in.html (accessed on 2 July 2017).

(C) 2017 by the authors. Licensee MDPI, Basel, Switzerland. This article is an open access article distributed under the terms and conditions of the Creative Commons Attribution (CC BY) license (http:/ / creativecommons.org/licenses/by/4.0/). 